\title{
Radiofrequency Ablation of Hepatocellular Carcinoma: Pros and Cons
}

\author{
Hyunchul Rhim and Hyo K. Lim \\ Department of Radiology and Center for Imaging Science, Samsung Medical Center, Sungkyunkwan University School of Medicine, Seoul, \\ Korea
}

Among locoregional treatments for hepatocellular carcinoma (HCC), radiofrequency ablation (RFA) has been accepted as the most popular alternative to curative transplantation or resection, and it shows an excellent local tumor control rate and acceptable morbidity. The benefits of RFA have been universally validated by the practice guidelines of international societies of hepatology. The main advantages of RFA include 1) it is minimally invasive with acceptable morbidity, 2) it enables excellent local tumor control, 3) it has promising long-term survival, and 4) it is a multimodal approach. Based on these pros, RFA will play an important role in managing the patient with early $\mathrm{HCC}$ (smaller than $3 \mathrm{~cm}$ with fewer than four tumors). The main limitations of current RFA technology in hepatic ablation include 1) limitation of ablation volume, 2) technically infeasible in some tumors due to conspicuity and dangerous location, and 3) the heat-sink effect. Many technical approaches have been introduced to overcome those limitations, including a novel guiding modality, use of artificial fluid or air, and combined treatment strategies. RFA will continue to play a role as a representative ablative modality in the management of HCC, even in the era of targeted agents. (Gut Liver 2010;4(Suppl. 1):S113-118)

Key Words: Radiofrequency ablation; Hepatocellular carcinoma; Image-guided tumor ablation; Thermal ablation; Loco-regional therapy

\section{INTRODUCTION}

Hepatocellular carcinoma (HCC) is the third most common cause of death of cancer worldwide. ${ }^{1-3}$ The curative treatment of HCC is transplantation or surgical resection. However, most of patients with HCC could not be a candidate for those curative options because of the shortage of donor organs, poor hepatic reserve, or multifocal diseases. ${ }^{3-9}$ For those patients with unrectable HCCs, there are many non-surgical treatments introduced. ${ }^{10-19}$ The image-guided loco-regional treatment for patients with unresectable HCC includes chemical or thermal ablative techniques and catheter-based treatments. Among the ablative techniques, radiofrequency ablation (RFA) has been used as the most popular method for treating early stage HCC. During the past two decades, many clinical studies have confirmed the safety and therapeutic efficacy of RFA. ${ }^{20-29}$ The purpose of this article is to review the current status of RFA for HCC by presenting the pros and cons. The current and potential roles and limitation of RFA in treating HCC will be addressed.

\section{PROS OF RFA FOR HCC}

As RFA is still an evolving technique, it is difficult to define the current role of RFA in the treatment of HCC. However, RFA is widely accepted as the most important ablative modality from the major academic societies (European Association of Study of Liver [EASL], American Association of Study of the Liver Disease [AASLD], Japanese Society of Hepatology). ${ }^{3,6,9,10}$ In the guidelines proposed by EASL and AASLD, RFA is recommended as a non-surgical technique for the treatment of early stage (Child A or B, solitary HCC or up to 3 nodules $<3 \mathrm{~cm}$ in size) HCC (Fig. 1). Since the introduction of RF technology in the field of interventional oncology, RFA is get-

\footnotetext{
Correspondence to: Hyuchul Rhim

Department of Radiology and Center for Imaging Science, Samsung Medical Center, Sungkyunkwan University School of Medicine,

50 Irwon-dong, Gangnam-gu, Seoul 135-710, Korea

Tel: +82-2-3410-2507, Fax: +82-2-3410-2559, E-mail: rhimhc@skku.edu

DOI: $10.5009 /$ gnl.2010.4.S1.S113
} 


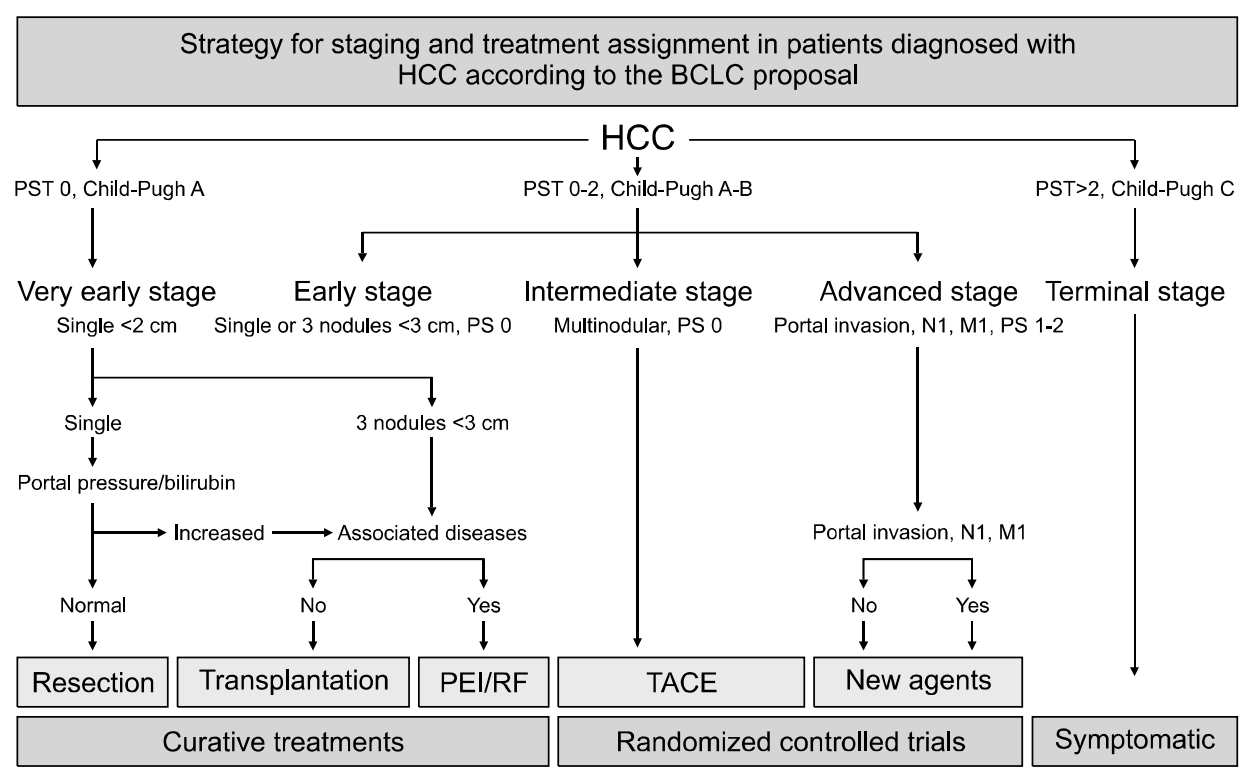

Fig. 1. Strategy for staging and treatment assignment in patient with hepatocellular carcinoma (HCC) according to the BCLC criteria. BCLC staging system was developed based on the collection of data from several independent studies representing different disease stages and/or treatment modalities. It includes variables related to tumor stage, liver functional status, physical status and cancer related symptoms. The main advantage of the BCLC criteria staging system is that it links staging with treatment modalities and with an estimation of life expectancy that is based on published response rates to the various treatments. Early stage disease includes patients with preserved liver function (Child-Pugh Class A and B) with solitary HCC or up to 3 nodules $<3 \mathrm{~cm}$ in diameter. These patients can be effectively treated by resection, transplantation, or percutaneous ablation with the possibility for long-term survival ranging from $50 \%$ to $75 \%$.

ting a consensus of the most valuable ablative method for unresectable HCC because of the following reasons: i) Minimally invasiveness with acceptable morbidity, ii) excellent local tumor control power, iii) favorable overall survival gain, iv) potential to be one of multimodality treatment.

\section{Minimally invasiveness with acceptable morbid- ity}

Minimally invasiveness of RFA procedure is the most important advantages compared to surgical resection especially for the patients with poor liver function. Most procedure can be performed under local and conscious sedation and on the out-patient or 2-3 days hospitalization basis. Several multicenter studies on the complications in patients after RFA procedures for hepatic tumors have proven the safety of RFA procedure. ${ }^{21-27}$ An extensive meta-analysis of 82 independent reports including 3,670 patients, reported by Mulier et al., revealed that the overall mortality rate was $0.5 \%$, and major/minor complication rate was $8.9 \%$. The most common complications were abdominal hemorrhage, abdominal infection (abscess), biliary tract damage, liver failure, pulmonary complications, and ground pad burns. The broad spectrum and incidence of major complications are similar to the findings of many single center studies. Two multicenter studies from Italy and Korea showed similar mortality and morbidity. Many large-series studies demonstrated that RFA is a safe procedure showing acceptable morbidity and mortality (Table 1). Although RFA is considered to be much safer than surgical treatment, it is not a complication-free procedure. Thus, an operator should be aware of all major complications with the potential morbidity and mortality, and should be ready to detect complications as early as possible and mange them appropriately.

\section{Excellent local tumor control}

The local tumor control is the primary goal of ablative therapy. RFA can make a reproducible ablation zones within 10-15 minutes. The average ablation zones by currently available RF electrodes are $3-4 \mathrm{~cm}$ in maximum diameter depending on the devices and ablation parameters. However, there are insufficient data and experiences to prove which energy or device is superior or inferior. Superior results can be due to ablation technique and/or tumor biology in the study group. The difference of the results is modest, and it can be overcome by technique.

Many meta-analysis studies demonstrated that RFA is superior to PEI in terms of local tumor control and the 
Table 1. Summary of Therapeutic Results of 6 Large Series Cohort Studies with Percutaneous RFA Alone

\begin{tabular}{|c|c|c|c|c|c|c|c|c|c|c|c|c|}
\hline \multirow{2}{*}{ Year } & \multirow{2}{*}{ Author } & \multirow{2}{*}{$\begin{array}{l}\text { No. of } \\
\text { patients }\end{array}$} & \multirow{2}{*}{$\begin{array}{l}\text { Size, } \\
\mathrm{cm}^{*}\end{array}$} & \multirow{2}{*}{$\mathrm{Fo}^{\dagger}$} & \multirow{2}{*}{$\underset{\%}{{ }_{\%}^{\text {LTP }}}$} & \multirow{2}{*}{$\begin{array}{l}\text { New } \\
\text { recur, } \\
\%^{\$}\end{array}$} & \multirow{2}{*}{$\begin{array}{l}\text { Major } \\
\text { Cx, \%" }\end{array}$} & \multicolumn{3}{|c|}{ Overall survival, \% } & \multirow{2}{*}{$\begin{array}{c}\text { Median } \\
\text { survival, } \\
\text { mo }\end{array}$} & \multirow{2}{*}{ Evidence } \\
\hline & & & & & & & & $1 \mathrm{yr}$ & $3 \mathrm{yr}$ & $5 \mathrm{yr}$ & & \\
\hline 2005 & Lencioni & 206 & $<5$ & 24 & 10 & 49 & 2.0 & 97 & 67 & 41 & 57 & 2 \\
\hline 2005 & Tateishi & 319 & $<5$ & 28 & 8.7 & 60 & 4.0 & 95 & 78 & 54 & NA & 2 \\
\hline 2006 & Chen & 256 & $<8$ & $2-69$ & NA & NA & 2.4 & 83 & 67 & 41 & NA & 2 \\
\hline 2007 & Choi & 570 & $<5$ & 30 & 11.8 & 52 & 1.9 & 95 & 70 & 58 & 77 & 2 \\
\hline 2008 & Livraghi & 216 & $<2$ & 31 & 0.9 & NA & 1.8 & NA & 76 & 55 & NA & 2 \\
\hline 2009 & N'Kontchou & 235 & $<5$ & 27 & 11.5 & 42 & 0.9 & NA & 60 & 40 & 48 & \\
\hline
\end{tabular}

RFA, radiofrequency ablation.

${ }^{*}$ Maximum diameter of tumor; ${ }^{\dagger}$ Mean follow-up period; ${ }^{\dagger}$ Rate of local tumor progression; ${ }^{\$}$ Rate of new recurrence including intrahepatic remote and extrahepatic metastasis; "Rate of major complications requiring additional hospitalization or therapeutic procedure; 'Level of evidence.

Table 2. Summary of 6 Clinical Studies on Comparison between RFA and Surgical Resection

\begin{tabular}{|c|c|c|c|c|c|c|c|c|c|c|c|c|c|}
\hline \multirow{2}{*}{ Year } & \multirow{2}{*}{ Author } & \multirow{2}{*}{ Study } & \multirow{2}{*}{ Treatment } & \multirow{2}{*}{$\begin{array}{l}\text { No. of } \\
\text { patients }\end{array}$} & \multirow{2}{*}{$\begin{array}{l}\mathrm{FU} \\
\text { mo* }\end{array}$} & \multirow{2}{*}{$\begin{array}{l}\text { Tumor } \\
\text { size, cm }\end{array}$} & \multicolumn{5}{|c|}{ Overall survival, \% } & \multirow{2}{*}{ p-value } & \multirow{2}{*}{ Evidence } \\
\hline & & & & & & & $1 \mathrm{yr}$ & $2 \mathrm{yr}$ & $3 \mathrm{yr}$ & $4 \mathrm{yr}$ & $5 \mathrm{yr}$ & & \\
\hline \multirow{2}{*}{2004} & \multirow{2}{*}{ Vivarelli } & \multirow{2}{*}{ NR } & RFA & 79 & \multirow{2}{*}{29} & \multirow{2}{*}{$<5$} & 78 & NA & 33 & NA & NA & \multirow{2}{*}{0.020} & \multirow{2}{*}{2} \\
\hline & & & Resection & 79 & & & 88 & NA & 65 & NA & NA & & \\
\hline \multirow{2}{*}{2005} & \multirow{2}{*}{ Montorsi } & \multirow{2}{*}{ NR } & RFA & 58 & \multirow{2}{*}{$\mathrm{NA}^{\ddagger}$} & \multirow{2}{*}{$<5$} & 85 & 75 & 61 & 45 & NA & \multirow{2}{*}{0.139} & \multirow{2}{*}{2} \\
\hline & & & Resection & 48 & & & 84 & 79 & 73 & 61 & NA & & \\
\hline \multirow{2}{*}{2005} & \multirow{2}{*}{ Hong } & \multirow{2}{*}{ NR } & RFA & 55 & \multirow{2}{*}{35} & \multirow{2}{*}{$<5$} & 100 & NA & 74 & NA & NA & \multirow{2}{*}{0.240} & \multirow[b]{2}{*}{2} \\
\hline & & & Resection & 93 & & & 98 & NA & 84 & NA & NA & & \\
\hline \multirow{2}{*}{2005} & \multirow{2}{*}{ Chen } & \multirow{2}{*}{$\mathrm{R}$} & RFA & 47 & \multirow{2}{*}{36} & & 93 & 82 & 64 & NA & NA & & \\
\hline & & & Resection & 65 & & $<5$ & 93 & 86 & 67 & NA & NA & 0.753 & 1 \\
\hline & & & RFA & 51 & & & 94 & 87 & 87 & NA & NA & & 1 \\
\hline 2008 & $\mathrm{Lu}$ & $\mathrm{R}$ & Resection & 54 & NA & $<5$ & 91 & 86 & 86 & NA & NA & 0.808 & 1 \\
\hline 2009 & Ueno & NR & RFA & 110 & 36 & & 98 & NA & 92 & NA & 63 & 0060 & 2 \\
\hline 2009 & Ueno & NR & Resection & 123 & 36 & $<b$ & 99 & NA & 92 & NA & 80 & 0.060 & 2 \\
\hline
\end{tabular}

RFA, radiofrequency ablation; R, randomized; NR, non-randomized.

${ }^{*}$ Mean follow-up period; ${ }^{\dagger}$ Level of evidence; ${ }^{\ddagger}$ Not available.

guideline proposed by major scientific societies approved the superiority of RFA over PEI. ${ }^{30-36}$ The local tumor progression rate after RFA ranged from $0.9 \%$ to $11.8 \%$ (Table 1). ${ }^{14-19}$ The prognostic factors on local tumor progression are the size of tumor, tumor abutting the larger vessel. The tumor size is the main factor for successful local tumor control. Thus, combined treatment with TACE or novel thermosensitive drug may be a good alternative for the large tumors more than $3 \mathrm{~cm}$ in diameter.

\section{Promising long-term survival gain}

Many clinical studies regarding the long-term results showed that RFA provided the favorable long-term survival gain for the patients with HCC. Since 2005, six clinical cohort studies with large series of patients (more than 200 patients) have been reported in the medical literature. $^{14-19}$ The survival results are summarized in Table 1 . The 5 year survival rates are reported from $41 \%$ to $68 \%$ depending on the tumor size, which are quite comparable to those of surgical resection. Based on the recent data, RFA is considered as one of curative option especially for the small sized single $\operatorname{HCC}(<2 \mathrm{~cm})$ in the many scientific societies. The proven prognostic factors in the literatures are Child-Pugh class, Pre-procedural AFP level, age, etc. After introduction of percutaneous ablation therapy, the efficacy compared with curative treatment, namely, surgical resection, for the treatment of small HCC has been debated. The therapeutic efficacy reported by these comparative studies of RFA and surgical resection are summarized in Table $2 .{ }^{37-42}$ Direct comparison by a well designed randomized controlled trial is the only way to assess whether RFA might replace surgical resection for treating early stage, resectable HCC. The difference in survival between the two treatments appears to be fairly small based on the currently available data. The sample size required to ensure meaningful conclusions 
should be quite large. Thus, this kind of randomized controlled study may be not feasible.

\section{One of multi-modality approach}

HCC is not a tumor which can be controlled completely by single treatment even if using transplantation. Hence, we should be wise to take a multi-modality treatment strategies. Given that context, RFA is a good therapeutic modality to provide a promising local tumor control. If a patient has a bilobar tumors, we can take the one lobe with major tumor and simultaneously ablation the remained minor tumor in the contralateral lobe in the same operating fields. If the tumor size is over than $5 \mathrm{~cm}$, we can combine TACE with RFA to achieve complete local tumor control. For the recurrent tumor after the curative surgical resection or transplantation, we can control the tumor successfully with minimal morbidity. ${ }^{43-45}$

\section{CONS OF RFA FOR HCC}

Although RFA has many pros for treating the patient with HCC, RFA has several limitations and pitfalls to be overcome. They include i) limited ablation volume, ii) technically difficult tumors, iii) heat-sink effect, iv) miscellaneous, etc.

\section{Limited ablation volume}

Even using the currently available RF technology, the ablation zone is limited upto $4-5 \mathrm{~cm}$ in maximum diameter. Unfortunately, the ablation zone at in-vivo condition usually decreases due to tissue mediated perfusion. ${ }^{46-49}$ Furthermore, the incidence of micro-satellite nodules around the main tumor tends to be increase as the tumor size increases. Thus, we need to use multiple electrodes or overlapping ablations with single electrode for achieving enough $(5-10 \mathrm{~mm})$ ablative margin surrounding the index tumor. Both solutions has a cost-effectiveness for multiple electrodes and a technically difficulty due to worsening sonic window for overlapping ablations.

\section{Technically infeasible tumors}

There are many conditions to be technically infeasible for successful ablation. ${ }^{50-57}$ The tumor with poor conspicuity is the most common cause of technically infeasible tumor if we use ultrasound as a guiding modality. In this case, we can use contrast-enhanced ultrasound to enhance the conspicuity of index tumor or use CT or MR guidance. If the tumor is located close to the organ, the collateral thermal injury can develop. Most vulnerable organ is the colon, diaphragm, gallbladder, main bile duct. For minimizing thermal injury to the gastrointestinal tract and diaphragm, we can use artificial fluid or air to separate the dangerous organ from the ablation zone. Artificial ascites assisted RFA is getting popular in treating the tumor located at the hepatic dome as artificial ascites can improve the sonic window as well as decrease the thermal injury by displacing the liver downward. To minimize thermal injury to the main bile duct, we can use biliary cooling through a naso-biliary catherter during ablation. If the tumor is too exophytic, it is hard to find normal hepatic parenchyma for RF electrode path. It is better to take another alternative such as TACE because the direct puncture of exophytic tumor can increase the possibility of tumor seeding.

\section{Heat sink effect}

Heat sink effect is a well known phenomenon affecting the negative effect on thermal ablation. ${ }^{55-57}$ The convected heat from the adjacent large vessel can decrease the ablation effect which finally resulting in local tumor progression during the follow-up. There are several tips introduced in the literatures. Pringle's maneuver is an established method to minimize the heat-sink effect when we treat the tumor abutting the large vessel. However, open laparotomy is required for this technique. Angiographic technique using balloon catheter has been introduced, but is not popularized. Combined PEI can be an alternative especially for the perivascular site of tumor.

\section{Miscellaneous}

Needle track seeding is a well known complication of RFA. ${ }^{22-28}$ However, it can be decrease if we traverse the normal parenchyma and coagulate the tract enough when removing the electrode. The one of the remaining cons is intravascular spreading of tumor by increasing intratumoral pressure during ablation. When using multi-tined electrode, stepwise deployment of internal prongs can decrease the intratumoral pressure increasement.

\section{SUMMARY}

Radiofrequency ablation is the most popular non-surgical technique for treating early stage unresectable HCC because of its excellent local tumor control and acceptable morbidity. Radiofrequency ablation is superior to PEI in terms of local tumor control and survival. Overall survival of radiofrequency ablation is comparable to surgical resection in a selected group of patients with smaller tumors. The most important advantages of RFA is the minimal invasiveness, favorable local tumor control power, promising long-term survival gain, and one of multi- 
modality treatment. The cons to be overcome includes the limited ablation volume using current RF technology, substantial proportion of technically infeasible tumors, and heat-sink effect. In conclusion, RFA will play a role of main stream as a local ablative technique in the era of multi-modality treatment of HCC.

\section{REFERENCES}

1. Bosch FX, Ribes J, Cleries R, Diaz M. Epidemiology of hepatocellular carcinoma. Clin Liver Dis 2005;9:191-211.

2. Stuart KE, Anand AJ, Jenkins RL. Hepatocellular carcinoma in the United States. Prognostic features, treatment outcome, and survival. Cancer 1996;77:2217-2222.

3. Bruix J, Sherman M. Management of hepatocellular carcinoma. Hepatology 2005;42:1208-1236.

4. Hong K, Georgiades CS, Geschwind JF. Technology insight: Image-guided therapies for hepatocellular carcinoma--intra-arterial and ablative techniques. Nat Clin Pract Oncol 2006;3:315-324.

5. Jansen MC, van Hillegersberg R, Chamuleau RA, van Delden OM, Gouma DJ, van Gulik TM. Outcome of regional and local ablative therapies for hepatocellular carcinoma: a collective review. Eur J Surg Oncol 2005;31: 331-347.

6. Bruix J, Sherman M, Llovet JM, et al. Clinical management of hepatocellular carcinoma. Conclusions of the Barcelona-2000 EASL conference. European Association for the Study of the Liver. J Hepatol 2001;35:421-430.

7. Llovet JM, Bruix J. Novel advancements in the management of hepatocellular carcinoma in 2008. J Hepatol 2008; 48 Suppl 1:S20-S37.

8. Makuuchi M, Kokudo N. Clinical practice guidelines for hepatocellular carcinoma: the first evidence based guidelines from Japan. World J Gastroenterol 2006;12:828-829.

9. Kudo M, Okanoue T. Management of hepatocellular carcinoma in Japan: consensus-based clinical practice manual proposed by the Japan Society of Hepatology. Oncology 2007;72 Suppl 1:2-15.

10. Poon RT, Fan ST, Tsang FH, Wong J. Locoregional therapies for hepatocellular carcinoma: a critical review from the surgeon's perspective. Ann Surg 2002;235:466-486.

11. Dodd GD 3rd, Soulen MC, Kane RA, et al. Minimally invasive treatment of malignant hepatic tumors: at the threshold of a major breakthrough. Radiographics 2000; 20:9-27.

12. Dupuy DE, Goldberg SN. Image-guided radiofrequency tumor ablation: challenges and opportunities--part II. J Vasc Interv Radiol 2001;12:1135-1148.

13. Lencioni R, Della Pina C, Bartolozzi C. Percutaneous image-guided radiofrequency ablation in the therapeutic management of hepatocellular carcinoma. Abdom Imaging 2005; 30:401-408

14. Lencioni R, Cioni D, Crocetti L, et al. Early-stage hepatocellular carcinoma in patients with cirrhosis: long-term results of percutaneous image-guided radiofrequency ablation. Radiology 2005;234:961-967.

15. Tateishi R, Shiina S, Teratani T, et al. Percutaneous radiofrequency ablation for hepatocellular carcinoma. An analy- sis of 1000 cases. Cancer 2005;103:1201-1209.

16. Chen MH, Yan K, Yang W, et al. Long term (5 years) outcome of radiofrequency ablation for hepatocellular carcino$\mathrm{ma}$ in 256 cases. Beijing Da Xue Xue Bao 2005;37: 671-672.

17. Choi D, Lim HK, Rhim H, et al. Percutaneous radiofrequency ablation for early-stage hepatocellular carcinoma as a first-line treatment: long-term results and prognostic factors in a large single-institution series. Eur Radiol 2007; 17:684-692.

18. Livraghi T, Meloni F, Di Stasi M, et al. Sustained complete response and complications rates after radiofrequency ablation of very early hepatocellular carcinoma in cirrhosis: Is resection still the treatment of choice? Hepatology 2008; 47:82-89.

19. N'Kontchou G, Mahamoudi A, Aout M, et al. Radiofrequency ablation of hepatocellular carcinoma: long-term results and prognostic factors in 235 Western patients with cirrhosis. Hepatology 2009;50:1475-1483.

20. Yan $\mathrm{K}$, Chen $\mathrm{MH}$, Yang $\mathrm{W}$, et al. Radiofrequency ablation of hepatocellular carcinoma: long-term outcome and prognostic factors. Eur J Radiol 2008;67:336-347.

21. Mulier S, Mulier P, Ni Y, et al. Complications of radiofrequency coagulation of liver tumours. Br J Surg 2002; 89:1206-1222.

22. Rhim H, Dodd GD 3rd, Chintapalli KN, et al. Radiofrequency thermal ablation of abdominal tumors: lessons learned from complications. Radiographics 2004;24:41-52.

23. Rhim H. Complications of radiofrequency ablation in hepatocellular carcinoma. Abdom Imaging 2005;30:409-418.

24. Livraghi T, Solbiati L, Meloni MF, Gazelle GS, Halpern EF, Goldberg SN. Treatment of focal liver tumors with percutaneous radio-frequency ablation: complications encountered in a multicenter study. Radiology 2003;226:441-451.

25. de Baere T, Risse O, Kuoch V, et al. Adverse events during radiofrequency treatment of 582 hepatic tumors. AJR Am J Roentgenol 2003;181:695-700.

26. Lencioni R, Veltri A, Gugliemmi A, et al. Complications of percutaneous radiofrequency ablation of liver malignancies with expandable multi-tined needles: results of a multicenter study. Presented at: The 86th Meeting of the Radiological Society of North America; 2000 Nov 26-Dec 1; Chicago, IL, USA.

27. Rhim H, Yoon KH, Lee JM, et al. Major complications after radio-frequency thermal ablation of hepatic tumors: spectrum of imaging findings. Radiographics 2003;23:123134; discussion 134-126.

28. Kondo Y, Yoshida H, Shiina S, Tateishi R, Teratani $T$, Omata M. Artificial ascites technique for percutaneous radiofrequency ablation of liver cancer adjacent to the gastrointestinal tract. Br J Surg 2006;93:1277-1282.

29. Chen MH, Yang W, Yan K, et al. Radiofrequency ablation of problematically located hepatocellular carcinoma: tailored approach. Abdom Imaging 2008;33:428-436.

30. Lencioni RA, Allgaier HP, Cioni D, et al. Small hepatocellular carcinoma in cirrhosis: randomized comparison of radio-frequency thermal ablation versus percutaneous ethanol injection. Radiology 2003;228:235-240.

31. Lin SM, Lin CJ, Lin CC, Hsu CW, Chen YC. Radiofrequency ablation improves prognosis compared with ethanol injection for hepatocellular carcinoma $<$ or $=4 \mathrm{~cm}$. Gas- 
troenterology 2004;127:1714-1723.

32. Lin SM, Lin CJ, Lin CC, Hsu CW, Chen YC. Randomised controlled trial comparing percutaneous radiofrequency thermal ablation, percutaneous ethanol injection, and percutaneous acetic acid injection to treat hepatocellular carcinoma of $3 \mathrm{~cm}$ or less. Gut 2005;54:1151-1156.

33. Shiina $S$, Teratani T, Obi $S$, et al. A randomized controlled trial of radiofrequency ablation with ethanol injection for small hepatocellular carcinoma. Gastroenterology 2005;129: 122-130.

34. Brunello F, Veltri A, Carucci P, et al. Radiofrequency ablation versus ethanol injection for early hepatocellular carcinoma: A randomized controlled trial. Scand J Gastroenterol 2008:43:727-735

35. Cho YK, Kim JK, Kim MY, Rhim H, Han JK. Systematic review of randomized trials for hepatocellular carcinoma treated with percutaneous ablation therapies. Hepatology 2009;49:453-459.

36. Bouza C, Lopez-Cuadrado T, Alcazar R, Saz-Parkinson Z, Amate JM. Meta-analysis of percutaneous radiofrequency ablation versus ethanol injection in hepatocellular carcinoma. BMC Gastroenterol 2009;9:31.

37. Vivarelli M, Guglielmi A, Ruzzenente A, et al. Surgical resection versus percutaneous radiofrequency ablation in the treatment of hepatocellular carcinoma on cirrhotic liver. Ann Surg 2004;240:102-107.

38. Montorsi M, Santambrogio R, Bianchi P, et al. Survival and recurrences after hepatic resection or radiofrequency for hepatocellular carcinoma in cirrhotic patients: a multivariate analysis. J Gastrointest Surg 2005;9:62-67.

39. Hong SN, Lee SY, Choi MS, et al. Comparing the outcomes of radiofrequency ablation and surgery in patients with a single small hepatocellular carcinoma and well-preserved hepatic function. J Clin Gastroenterol 2005;39: 247-252.

40. Lü MD, Kuang M, Liang LJ, et al. Surgical resection versus percutaneous thermal ablation for early-stage hepatocellular carcinoma: a randomized clinical trial. Zhonghua Yi Xue Za Zhi 2006;86:801-805.

41. Ueno S, Sakoda M, Kubo F, et al. Surgical resection versus radiofrequency ablation for small hepatocellular carcinomas within the Milan criteria. J Hepatobiliary Pancreat Surg 2009;16:359-366.

42. Hasegawa K, Makuuchi M, Takayama T, et al. Surgical resection vs. percutaneous ablation for hepatocellular carcinoma: a preliminary report of the Japanese nationwide survey. J Hepatol 2008;49:589-594.

43. Choi D, Lim HK, Joh JW, et al. Combined hepatectomy and radiofrequency ablation for multifocal hepatocellular carcinomas: long-term follow-up results and prognostic factors. Ann Surg Oncol 2007;14:3510-3518.

44. Poon RT. Radiofrequency ablation combined with resection enhances chance for curative treatment of hepatocellular carcinoma. Ann Surg Oncol 2007;14:3299-3300.
45. Abdalla EK, Vauthey JN, Ellis LM, et al. Recurrence and outcomes following hepatic resection, radiofrequency ablation, and combined resection/ablation for colorectal liver metastases. Ann Surg 2004;239:818-825.

46. Goldberg SN, Grassi CJ, Cardella JF, et al. Image-guided tumor ablation: standardization of terminology and reporting criteria. J Vasc Interv Radiol 2005; 16:765-778.

47. Lee JM, Han JK, Kim HC, et al. Multiple-electrode radiofrequency ablation of in vivo porcine liver: comparative studies of consecutive monopolar, switching monopolar versus multipolar modes. Invest Radiol 2007;42:676-683.

48. Hansler J, Frieser M, Tietz V, et al. Percutaneous ultrasound-guided radiofrequency ablation (RFA) using saline-perfused (wet) needle electrodes for the treatment of hepatocellular carcinoma--long term experience. Ultraschall Med 2007;28:604-611.

49. Lee JM, Han JK, Kim SH, et al. A comparative experimental study of the in-vivo efficiency of hypertonic saline-enhanced hepatic bipolar and monopolar radiofrequency ablation. Korean J Radiol 2003;4:163-169.

50. Rhim H, Lim HK, Kim YS, Choi D. Percutaneous radiofrequency ablation with artificial ascites for hepatocellular carcinoma in the hepatic dome: initial experience. AJR Am J Roentgenol 2008;190:91-98.

51. Yamakado K, Nakatsuka A, Akeboshi M, Takeda K. Percutaneous radiofrequency ablation of liver neoplasms adjacent to the gastrointestinal tract after balloon catheter interposition. J Vasc Interv Radiol 2003;14:1183-1186.

52. Uehara $T$, Hirooka $M$, Ishida $K$, et al. Percutaneous ultrasound-guided radiofrequency ablation of hepatocellular carcinoma with artificially induced pleural effusion and ascites. J Gastroenterol 2007;42:306-311.

53. Shibata T, Iimuro Y, Ikai I, Hatano E, Yamaoka Y, Konishi J. Percutaneous radiofrequency ablation therapy after intrathoracic saline solution infusion for liver tumor in the hepatic dome. J Vasc Interv Radiol 2002;13:313-315.

54. Dodd GD 3rd, Frank MS, Aribandi M, Chopra S, Chintapalli $\mathrm{KN}$. Radiofrequency thermal ablation: computer analysis of the size of the thermal injury created by overlapping ablations. AJR Am J Roentgenol 2001;177:777-782.

55. Song I, Rhim H, Lim HK, Kim YS, Choi D. Percutaneous radiofrequency ablation of hepatocellular carcinoma abutting the diaphragm and gastrointestinal tracts with the use of artificial ascites: safety and technical efficacy in 143 patients. Eur Radiol 2009;19:2630-2640.

56. Kim SK, Lim HK, Ryu JA, et al. Radiofrequency ablation of rabbit liver in vivo: effect of the pringle maneuver on pathologic changes in liver surrounding the ablation zone. Korean J Radiol 2004;5:240-249.

57. de Baere T, Deschamps F, Briggs P, et al. Hepatic malignancies: percutaneous radiofrequency ablation during percutaneous portal or hepatic vein occlusion. Radiology 2008;248:1056-1066. 